\title{
Assessment of aflatoxin B1 in livestock feed and feed ingredients by high-performance thin layer chromatography
}

\author{
Korrapati Kotinagu, T. Mohanamba and L. Rathna Kumari \\ Toxicology and Feed Analysis Laboratory Veterinary Biological Research Institute, Shanti Nagar, Hyderabad, \\ Telangana, India. \\ Corresponding author: Korrapati Kotinagu, e-mail: kotinagu@gmail.com, TM: tfalvbri@gmail.com, \\ LRK: jddivbri@gmail.com \\ Received: 16-07-2015, Revised: 16-10-2015, Accepted: 23-10-2015, Published online: 17-12-2015
}

doi: 10.14202/vetworld.2015.1396-1399 How to cite this article: Kotinagu K, Mohanamba T, Kumari LR (2015) Assessment of aflatoxin B1 in livestock feed and feed ingredients by high-performance thin layer chromatography, Veterinary World 8(12): 1396-1399.

\begin{abstract}
Aim: Detection of aflatoxin B1 in Livestock compound Feed and feed ingredients by high-performance thin layer chromatography (HPTLC).

Materials and Methods: Chromatography was performed on HPTLC silica gel 60 F 254, aluminum sheets by CAMAG automatic TLC sampler 4, with mobile phase condition chloroform:acetone:water (28:4:0.06). Extraction of aflatoxin B1 from samples was done as per AOAC method and screening and quantification done by HPTLC Scanner 4 under wavelength $366 \mathrm{~nm}$.

Results: A total of 97 livestock feed (48) and feed ingredients (49) samples received from different livestock farms and farmers were analyzed for aflatoxin B1 of which 29 samples were contaminated, constituting 30\%. Out of 48 livestock compound feed samples, aflatoxin B1 could be detected in 16 samples representing 33\%, whereas in livestock feed ingredients out of 49 samples, 13 found positive for aflatoxin B1 representing $24.5 \%$.

Conclusion: HPTLC assures good recovery, precision, and linearity in the quantitative determination of aflatoxin B1 extracted from Livestock compound feed and feed ingredients. As more number of feed and feed ingredients are contaminated with aflatoxin B1 which causes deleterious effects in both animal and human beings, so there is a need for identifying the source of contamination, executing control measures, enabling better risk assessment techniques, and providing economic benefits.
\end{abstract}

Keywords: aflatoxin B1, animal feed, feed ingredients, high-performance thin layer chromatography.

\section{Introduction}

Mycotoxins are structurally fungal metabolites produced by Fungi, not essential to fungal growth and produced periodically under fungal stress. They can contaminate a variety of mixed feed and food leading to animal and human health specific component species such as Aspergillus, Fusarium, and Penicilliumare able to produce these toxins that account per annum for millions of dollars in losses worldwide in condemned agriculture products [1].

Fungal metabolites generally associated with fungi belonging to the genera Alternaria, Aspergillus, Fusarium, and Penicillium. Toxigenic Alternaria and Fusarium species are often classified as field fungi, while Aspergillus and Penicillium species are considered storage fungi. The most common Fusarium mycotoxins are trichothecenes, zearalenone, and fumonisins. The mycotoxins of interest produced by Aspergillus species include aflatoxin and ochratoxin A, while Penicillium species produces ochratoxin A, citrinin and patalin among the more important mycotoxins [2].

Among the mycotoxins that are known to cause human diseases, aflatoxin has been studied most [3].

Copyright: The authors. This article is an open access article licensed under the terms of the Creative Commons Attributin License (http:// creative commons.org/licenses/by/2.0) which permits unrestricted use, distribution and reproduction in any medium, provided the work is properly cited.
Aflatoxin was discovered some 30 years ago in England following a poisoning outbreak causing 100,000 turkeys death. Fungi produce aflatoxin in the presence of higher moisture, temperature, and adequate substratum. Before harvest, the risk for the development of aflatoxin is greatest during major droughts, where soil moisture is below normal and temperatures are high, the number of Aspergillus spores in the air increases. These spores infect crops through areas of damage caused by insects, and inclement weather. Once injected, plant stress occurs; the production of aflatoxin is favored. During postharvest stage, proliferation of aflatoxin can be exacerbated in susceptible environment [4]. Today aflatoxin has been one of the most important global concerns regarding contamination of food products [5].

Taking into account the development in Codex alimentarius, recently EC has introduced the maximum accepted/residue levels for aflatoxin inanimal feeds as $0.02 \mathrm{mg} / \mathrm{kg}$, i.e., $20 \mathrm{ppb}$ in all feed materials and in the most complete and complementary feedstuffs for cattle, sheep, goats, pigs and poultry, while it is $0.005 \mathrm{mg} / \mathrm{kg}$ in complete feeding stuffs for dairy animals and $0.01 \mathrm{mg} / \mathrm{kg}$ for complete feeding stuffs for calves and lambs [6].

Thin layer chromatography (TLC) techniques were extensively used for aflatoxin analysis, although recently an increase in the use of High-Performance 
TLC (HPTLC) has been noted. The accuracy of TLC is less than that of HPTLC, but the results obtained using HPTLC are similar to that of HPLC and a more consistent than Enzyme-linked immunosorbent assay data [7]. In the present study, we have analyzed the feed samples and feed ingredients by HPTLC for aflatoxin B1 contamination.

\section{Materials and Methods}

\section{Ethical approval}

There is no need of ethical approval for such type of study.

\section{Collection of samples}

The livestock feeds and feed ingredients received at toxicology and feed analytical laboratory, Veterinary Biological Research Institute, Hyderabad during the year 2014-2015 were utilized for the present study, A total of 97 livestock compound feeds and livestock feed ingredients received from all over the state of Andhra Pradesh and Telanaga were analyzed for the detection of aflatoxin B1.

\section{Method validation}

All the reagents were of analytical grade (HPLC). The mycotoxins standards, aflatoxin B1 were obtained from Sigma-Aldrich laborchemikalien. The standards were calibrated and checked for its purity by UV spectrophotometer (AOAC, 2000). The Mycotoxins standards solution used in the present study were dissolved in specific solvent (methanol). The extraction of sample were done as per AOAC method and quantified with reference standards by HPTLC.

Silica gel 60 F 254 (Merk, Darmstadt) HPTLC plates in the format of $10 \times 10$ or $20 \times 10$ were used for analysis. The samples after extraction and drying redissolved with $1 \mathrm{ml}$ of chloroform were applied as bands (spray-on Technique) using CAMAG Automatic TLC sampler 4 . The spotted plates were developed in presaturated Twin-trough chamber up to $80 \mathrm{~mm}$ from lower edge of the plate with Chloroform:Acetone: water (28:4:0.06) as a mobile phase. After development, the plates were dried using hair dryer and finally the plates were scanned in CAMAG HPTLC Scanner 4 under $366 \mathrm{~nm}$ wavelengths to determine the levels of aflatoxin B1 contamination in samples (Figure-1). The standard solutions were applied as the upper method, representing $0.5 \mathrm{ng}, 1 \mathrm{ng}, 1.5 \mathrm{ng}$, and $2 \mathrm{ng}$ aflatoxin B1 (Figure-2). The calibration curve of peak area against concentration was plotted (Figure-3). The limit of detection of aflatoxin B1 was $0.02 \mathrm{ng}$ and the limit of quantification $0.66 \mathrm{ng}$.

The quantification of fully separated aflatoxin B1 was performed by comparison with aflatoxin B1 standard using formula and checking the linearity.

Concentration of aflatoxin B1 in ppm:

Standard peak height $\times$ Sample peak height

Standard peak height

$\times$ Final volume of sample spotted

\section{Results and Discussion}

The recovery percentage of aflatoxin B1 was $90 \%$ in the present study. The contamination of aflatoxin B1 was found to be $33 \%$ in livestock compound feed and $24 \%$ in feed ingredients in the present study, among the livestock compound feed analyzed for aflatoxin B1, except Pig adult and creeper mash, all other were within the safe limit of Indian standards (cattle feed $=50 \mathrm{ppb}$ and pig and poultry feed $=20 \mathrm{ppb}$ ).

Among the 48 livestock compound feed samples analyzed (Table-1), 33\% (16 of 48) were contaminated with aflatoxin B1 among them $26 \%$ (6 of 23) cattle feed samples shown the mean concentration of $32 \mathrm{ppb}$ which was lower the Indian standards (50 ppb). In poultry feed, $35.2 \%$ incidence was found (6 of 17) at concentration of $13.4 \mathrm{ppb}$ which was below the Indian standards (20 ppb). An incidence of 66.6\% (2 of 3)

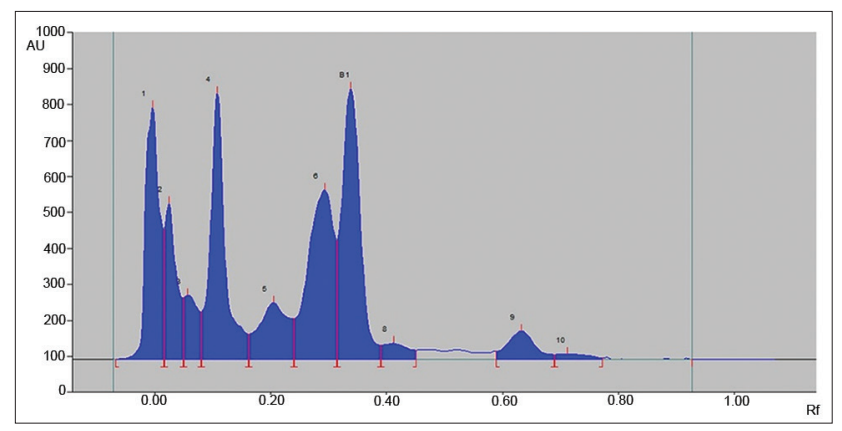

Figure-1: Elution pattern of aflatoxin $B 1$ in feed sample at $366 \mathrm{~nm}$ wavelength by CAMAG high-performance thin layer chromatography scanner.

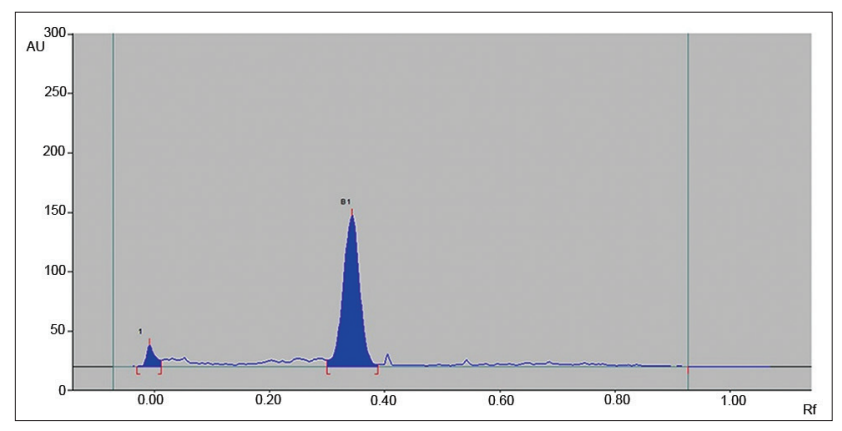

Figure-2: Elution pattern of aflatoxin B1 standard at $366 \mathrm{~nm}$ wavelength by CAMAG high-performance thin layer chromatography scanner.

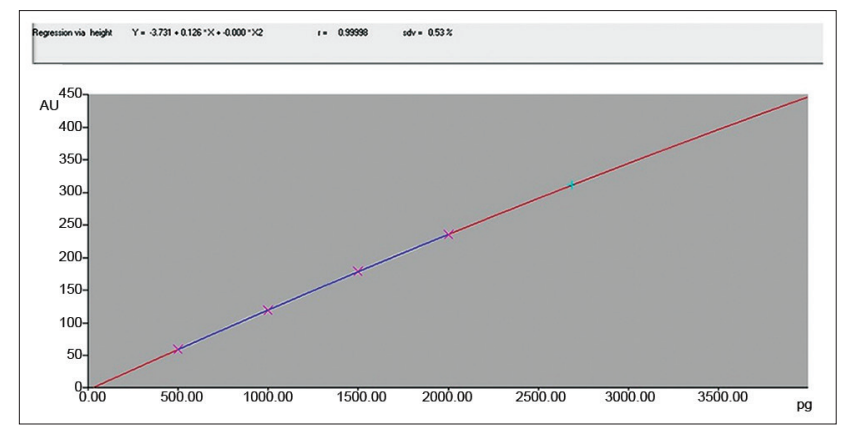

Figure-3: Calibration curve of aflatoxin B1 standard at $366 \mathrm{~nm}$ wavelength by CAMAG high-performance thin layer chromatography scanner. 
Table-1: Aflatoxin contamination in compound feed and feed ingredients.

\begin{tabular}{|c|c|c|c|c|c|}
\hline Feed/feed ingredients & No. of samples analyzed & No. of positives & Incidence & Mean (in ppb) & Range (in ppb) \\
\hline Compound feed & 48 & 16 & 33.3 & - & \\
\hline Cattle feed & 24 & 6 & 26 & 32 & $20-60$ \\
\hline Poultry feed & 17 & 6 & 35.2 & 13.4 & $10-20$ \\
\hline Pig creeper mash & 3 & 2 & 66.6 & 20 & $20-20$ \\
\hline Pig adult mash & 4 & 2 & 50 & 30 & $30-30$ \\
\hline Feed ingredients & 49 & 13 & 24.5 & - & \\
\hline Cotton seed cake & 7 & 3 & 42.8 & 23.3 & $10-40$ \\
\hline Groundnut cake & 5 & 3 & 60 & 23.3 & $20-30$ \\
\hline Soyabean cake & 3 & 1 & 33.3 & 50 & - \\
\hline Sunflower DOC & 3 & 1 & 33.3 & 10 & - \\
\hline Maize & 13 & 5 & 38.4 & 62 & - \\
\hline Wheat bran & 2 & 0 & 0 & - & - \\
\hline Red gram & 4 & 0 & 0 & - & - \\
\hline DO rice bran & 4 & 0 & 0 & - & - \\
\hline Jowar & 1 & 0 & 0 & - & - \\
\hline Feed by products & 7 & 0 & 0 & - & - \\
\hline Grand total & 97 & 29 & 30 & - & \\
\hline
\end{tabular}

was found in pig creeper mash with a mean concentration of $20 \mathrm{ppb}$ and in pig adult mash an incidence of $50 \%$ ( 2 of 4) with a mean concentration of $30 \mathrm{ppb}$ which is higher than the Indian standards for pig feed (20 ppb). Similar studies were conducted by Dhand et al.[8] in dairy cattle feeds and reported $75 \%$ of feed samples (21 of 28) were contaminated with aflatoxin B1. Our findings are in agreement with earlier reports, where aflatoxin B1 was found to be widely distributed in feed stuffs [9-11]. In a study by Sarathchandra and Muralimanohar [12], aflatoxin B1 levels ranged between 50 and $80 \mathrm{ppm}$ in animal feed. Out of 59 samples of feed analyzed by HPTLC, 47 samples were positive for aflatoxin B1 representing 79.66\% with a concentration of $25.53 \mathrm{ppb}$ [13].

For Feed ingredients (Table-1), 24.5\% (13 of 49) shown contamination of aflatoxin B1 in cotton seed cake, groundnut cake, soyabean cake, Sunflower de oiled cake, wheat bran, maize, red gram de oiled rice bran, jowar and feed by products. An incidence of $42.8 \%$ (3 of 7) with mean concentration of $23.3 \mathrm{ppb}$ of aflatoxin B1 was seen in Cotton seed cake. In groundnut cake, an incidence of $60 \%$ ( 3 of 5) was contaminated with mean concentration of $23.3 \mathrm{ppb}$. An incidence of $33.3 \%$ (1 of 3 ) soyabean cake was contaminated with aflatoxin $\mathrm{B} 1$ at a concentration of $50 \mathrm{ppb}$. In sunflower de oiled cake (1of 3) 33.3\% found positive for aflatoxin $\mathrm{B} 1$ at concentration of $10 \mathrm{ppb}$. The highest concentration was seen in maize sample with mean concentration of $62 \mathrm{ppb}$ showing incidence of 38.4 ( 5 of 13 samples). Maize, being the world's important staple food [14] has been extensively studied for mycotoxins contamination as it has been found (among cereals) a very good substrate for fungal growth and toxigenesis[15], our results are in accordance with other worldwide surveys indicate the contamination of maize with aflatoxin Janardhana et al.[16], Sangare-Tigori et al. [17] andKhatoon et al. [18]. Whereas wheat bran, red gram, de oiled rice bran, jowar and feed by products are free from aflatoxin B1 in the present study. In a study, Mahammadi et al.[19] reported that among 152 samples of rice analyzed, $75 \%$ showed levels of aflatoxin B1 contamination with the mean of $0.671 \mathrm{ppb}$.Substantiating the present results, Anjum et al.[20] reported the overall incidence of $6 \%$ of aflatoxin B1 with average and maximum contamination levels of 37.62 and $56 \mathrm{ppb}$, respectively.

The results revealed low average aflatoxin concentration than the permissible levels, for livestock compound feed samples and feed ingredients except Pig creeper mash, pig adult mash, soyabean cake and maize. The results of the present study showed a higher incidence and contamination of aflatoxin B1 in pig creeper mash, pig adult mash, soyabean cake and maize, fluctuations in environmental temperature and humidity, rainy season and moderate temperature during preharvest period, intermittent showers during harvesting traditional harvesting practices and inadequate storage facilities induce fungal contamination and accumulation of mycotoxins [21]. Aflatoxin B1 levels in animal feed and feed stuff are important to human health since approximately $1-2 \%$ of the aflatoxin $\mathrm{B} 1$ in the animal feed is transformed to aflatoxin M1 in milk. Therefore, aflatoxin B1 concentration in feed above standards may result in milk containing a higher aflatoxin M1 [22]. In developing countries, many individuals are chronically exposed to low levels of aflatoxins in their diet [23].

\section{Conclusion}

Our studies revealed that HPTLC assures good recovery, precision and linearity in the quantitative determination of aflatoxin B1 extracted from Livestock compound feed and feed ingredients. Our worked showed that $30 \%$ of livestock feed (33\%) and feed ingredients (24\%) were contaminated aflatoxin B1. There is a need for identifying the source of contamination, executing control measures, enabling 
better risk assessment techniques, and providing economic benefits.

\section{Authors' Contributions}

KK and MT have designed the plan of work. KK carried out the Laboratory work and analyzed the results. KK and TM drafted and RK revised the manuscript. All the authors read and approved the final manuscript.

\section{Acknowledgments}

The authors are thankful to The Director, Department of Animal Husbandry, Telangana for providing support and laboratory facilities to carry out this research.

\section{Competing Interests} interests.

The authors declare that they have no competing

\section{References}

1. Bouhet, S. and Oswald, I.P. (2005) The effects of mycotoxins, fungal food contaminants on the Intestinal epithelial cell - derived innate immune response. Vet. Immunol. Immunopathol., 108: 199-209.

2. Logrieco, A., Bottanico, A., Mule, G., Moretti, A. and Perrone, G. (2003) Epidemiology of toxigenic fungi and their associated mycotoxins for some mediterranean crops. Eur. J. Plant Pathol., 109(7): 645-674.

3. Ezekiel, C.N., Sulyok, M., Warth, B., Odebode, A.C. and Krska, R. (2012) Natural occurrence of mycotoxins in peanut cake from Nigegeria. Food Control.,27: 338-342.

4. Risk Assessment Studies. (2001) Report No. 5. An Evaluation of Aflatoxin Surveillance Findings in Hong Kong 1998 - 2000. Chemical Hazards Evaluation; Aflatoxin in Foods, Food and Environmental Hygiene Department, HKSAR. Available from: http://www.cfs.gov.hk/english/ programme/programme_rafs/files/report.pdf. Accessed on 23-09-2015.

5. Selim, M.I. (2010) Significance of aflatoxin in rural and global health. N C. Med. J., 71(5): 438-441.

6. Commission of European Communities. (2003) Commission directive 2003/100/EC. Offic. J. Euroommunit., 285: 33-37.

7. Jaimez, J., Fente, C.A., Vazquez, B.I., Franco, C.M., Cepeda, A., Mahuzier, G. and Prognon, P. (2000) Application of the assay of aflatoxins by liquid chromatography with fluorescence detection in food analysis. J. Chromatogr. A, 882(1-2): 1-10.

8. Dhand, N.K., Joshi, D.V. and Jand, S.K. (1998) Aflatoxins in dairy feeds/ingredients. Indian J. Anim. Nutr., 15(4): 285-286.
9. Alkhalaf, A., Khaled, N., Osman, A. and Salama, K.A. (2010) Monitoring of aflatoxin and heavy metals in poultry feed. Afr. J. Food Sci., 4: 192-199.

10. Saleemi, M.K., Khan, M.Z., Khan, A. and Javed, I. (2010) Mycoflora of poultry feed and mycotoxins producing potential of Aspergillus species. Pak. J. Bot., 42: 427-424.

11. Rawal, S., Kim, J.E. and Coulombe, R.J.R. (2010) Aflatoxin $\mathrm{B}_{1}$ in poultry toxicology, Metabolism and prevention. Res. Vet. Sci., 89(3): 325-331.

12. Sarathchandra, G. and Muralimanohar, B. (2013) Occurrence of mycotoxins in livestock feeds and feed stuffs of Tamil Nadu. J. Environ. Biol., 34: 825-830.

13. Ramesh, J., Sarathchandra, G. and Suresh Kumar, V. (2013) Analysis of feed samples for aflatoxin $\mathrm{B}_{1}$ contamination by HPTLC- A validation method. Int. J. Curr. Microbiol. Appl. Sci., 2(5): 373-377.

14. Anonymous. (2002) FAOSTAT Database. Food and Agricultural Organisation. Roma, Italy. Available from: http://www.apps.fao.org/pagecollectons. Accessed on 08-07-2015.

15. Trung, T.S., Tabuc, C., Bailly, S., Querin, A., Guerre, P. and Bailly, I.D. (2008) Fungal mycoflora and contamination of maize from Vietnam with Aflatoxin B1 and Fumonisim B1. World Mucotoxin J., 1(1): 87-94.

16. Janardhana, G.R., Raveesha, K.A. and Shetty, H.S. (1999) Mycotoxin contamination of maize grown in Karnataka (India). Food Chem. Toxicol., 37: 863-868.

17. Sangare-Tigori, B., Dem, A.A., Kouadio, H.J., Betbeder, A.M., Dano, D.S., Moukha, S. and Creppy, E.E. (2006) Co-occurrence of aflatoxin $B_{1}$, feminism B2, ochratoxin $\mathrm{A}$ and zearalenone in cereals and peanuts from Cete d'Ivoire. Hum. Exp. Toxicol., 25: 211-216.

18. Khatoon, S., Hanif, N.Q., Tharia, I., Sultana, N., Sultana, K. and Ayub, N. (2012) Natural occurrence of aflatoxins, zearalenone and trichothecenes in maize grown in Pakistan. Pak. J. Bot., 44(1): 231-236.

19. Mahammadi, M., Mohebbi, G.H., Akharzadeh, S. and Shojae, I. (2012) Detection of Aspergillus spp. and determination of Bushehr, Iran. Afr. J. Biotechnol., 11(38): 9230-9234.

20. Anjum, M.A., Khan, S.H., Sahota, A.W. and Sardar, R. (2012) Assessment of aflatoxin B1 in commercial poultry feed and feed ingredients. J. Anim. Plant Sci., 22(2): 268-72.

21. Memon, S.Q., Zakria, M., Mari, G.R., Nawaz, M.H. and Khan, M.Z. (2011) Effect of tillage methods and fertilizer levels on maize production. Pak. J. Agric. Sci., 48: 117-120.

22. Oruc, H.H., Cengiz, M. and Uzunoglu, I. (2007) Occurrence of aflatoxin B1, and $\mathrm{T} 2$ toxin in feed and ad raw ingredients used for animal feeding stuffs. Uludag. Univ. J. Vet. Med., 26: $1-5$.

23. Wild, C.P. and Gong, Y.Y. (2010) Mycotoxins and human diseases: A largely ignored global health issue. Carcinogenesis., 31: 71-82. 